\title{
ESTUDO PROSPECTIVO DA CASCA DE MARACUJÁ APLICADA COMO MEIO FILTRANTE NO TRATAMENTO DE ÁGUA PRODUZIDA
}

\author{
M. S. BISPO ${ }^{1 *}$, F. M. OLIVEIRA ${ }^{2}$, P. SANTOS ${ }^{1}$, J. A. C. SOUZA $^{3}$, A. G. B. FREITAS ${ }^{4}$, G. F. \\ SILVA $^{1}$; \\ ${ }^{1}$ Universidade Federal de Sergipe, Núcleo de Engenharia de Petróleo \\ ${ }^{2}$ Universidade Federal de Sergipe, Departamento de Engenharia Química \\ ${ }^{3}$ Universidade Federal de Sergipe, Departamento de Química \\ ${ }^{4}$ Universidade Federal do Rio de Janeiro, Escola de Química \\ "e-mail: mirele_sb@hotmail.com
}

\begin{abstract}
RESUMO
Através de estudos prospectivos, o presente trabalho teve como objetivo classificar os artigos científicos relacionados à casca do maracujá aplicada como meio filtrante no tratamento de água produzida. Para essa busca, utilizou-se as fontes de pesquisa: WEB OF SCIENCE®, SCIENCE DIRECT® e SCOPUS®. As palavras-chaves utilizadas foram: filtration and passion fruit, filtration and produced water, passion fruit and produced water, filtration and passion fruit and produced water, elas foram realizadas no mês de junho do presente ano, no escopo temporal de 2001 a 2015. Resultados significativos foram encontrados para a junção maracujá e água produzida chegando-se ao valor de 1204, somando-se todas as fontes de pesquisa, além disso, identificou-se 270 exemplares para filtração e maracujá. Em contrapartida, apenas 170 trabalhos foram encontrados com a combinação das três palavras-chaves, sendo estes disponíveis somente na SCIENCE DIRECT®. A partir da fonte SCOPUS® foi notório o predomínio de artigos publicados no Brasil, chegando-se a atingir $73 \%$ no caso da combinação água produzida e maracujá. Um ponto que ratificou a importância de mais pesquisas envolvendo tal tema foi observado através da constatação que as áreas mais abrangentes tanto para maracujá e água produzida quanto para filtração e maracujá são ciências agrárias e biológicas, ficando uma minoria restrita ao setor de tratamento de efluentes.
\end{abstract}

\section{INTRODUÇÃO}

O petróleo é um dos principais componentes da matriz energética mundial, os seus derivados são matérias-primas para as indústrias petroquímica e farmacêutica, abrangendo as mais diversas áreas. Entretanto, durante a sua extração a água produzida é obtida como subproduto, ao longo da produção o seu volume vai aumentando ao ponto de não ser mais economicamente viável a exploração do campo petrolífero, outro problema é a sua composição, de acordo com Stephenson (1991), os compostos que normalmente compõem esse efluente são: óleo disperso e dissolvido, sais minerais dissolvidos, sólidos oriundos da corrosão, graxas e asfaltenos, produtos químicos adicionados para prevenir e/ou tratar problemas operacionais, tais como: biocidas, anti-incrustantes, anti-espumantes e inibidores de corrosão, e gases dissolvidos, incluindo dióxido de carbono $\left(\mathrm{CO}_{2}\right)$ e gás sulfídrico $\left(\mathrm{H}_{2} \mathrm{~S}\right)$. Por conta disso, é necessário 
que esta passe por um tratamento específico a fim de se adequar as resoluções vigentes do órgão ambiental, que no caso do Brasil é o Conselho Nacional do Meio Ambiente (CONAMA), sendo possível realizar o seu posterior descarte, reinjeção ou reuso. Para atingir tal objetivo várias técnicas de tratamento são utilizadas, dentre elas pode-se citar a filtração, adsorção, eletroquímico, flotação, hidrociclones, etc.

Destacando-se a filtração, que é um processo imprescindível para a produção contínua e segura em diversos processos industriais. Esse processo pode ocorrer de forma rápida ou lenta, dependendo da taxa de filtração, teor dos contaminantes e qualidade final do produto ou efluente. A utilização de processos de filtração por membranas, tais como microfiltração, ultrafiltração, nanofiltração e osmose inversa oferecem muitas vantagens para o tratamento de água produzida (MONDAL, 2008). Um meio filtrante natural que pode vir a se tornar uma alternativa tecnicamente e economicamente viável é a casca de maracujá.

A finalidade do presente trabalho é analisar, a partir da prospecção tecnológica de artigos científicos, a casca do maracujá aplicada como meio filtrante no tratamento de água produzida. Essa busca é uma maneira de monitorar a importância do desenvolvimento de novas pesquisas e carências acerca de tal assunto. De acordo com Coelho (2003), o termo prospecção tecnológica designa atividades de prospecção centradas nas mudanças da capacidade funcional ou no tempo e com significado de uma inovação. Visa incorporar informações ao processo de gestão tecnológica, tentando predizer possíveis estados futuros da tecnologia ou condições que afetam sua contribuição para as metas estabelecidas. A prospecção tecnológica permite aos gestores posicionarem-se de modo a influenciar na orientação das trajetórias tecnológicas, o que, do ponto de vista evolucionista, significa lançar-se à frente e garantir a competitividade e a sobrevivência das instituições de P\&D e dos usuários de seus resultados.

\section{METODOLOGIA}

A prospecção foi baseada na pesquisa de artigos científicos, para isso fez-se uso das fontes de pesquisa: WEB OF SCIENCE®, SCIENCE DIRECT® e SCOPUS $® . \quad A s$ palavras-chaves foram: water produced, filtration e passion fruit. As buscas foram realizadas no mês de junho de 2015 no escopo temporal de 2001 a 2015, investigando os documentos de artigos depositados por país de origem, evolução temporal da tecnologia e áreas relacionadas. Cabe ressaltar que essas bases são acessíveis apenas em bibliotecas de universidades públicas federais.

No intuito de averiguar a utilização específica do maracujá como meio filtrante no tratamento de água produzida realizou-se as buscas combinadas da seguinte maneira: filtration and passion fruit, filtration and produced water, passion fruit and produced water, filtration and passion fruit and produced water, no campo de pesquisa do tópico. Os resultados obtidos foram recuperados e regulados por intermédio do software Excel conforme critérios estabelecidos para avaliação.

\section{RESULTADOS E DISCUSSÃO}

O período de pesquisa nas bases escolhidas deu enfoque aos artigos científicos mais atuais abrangendo os anos 2001 até 2015, totalizando 14 anos.

Como mostra a Figura 1, o número de artigos publicados em cada fonte de pesquisa de acordo com a combinação das palavraschaves: filtration and passion fruit, filtration and produced water, passion fruit and produced water, filtration and passion fruit and produced water, a quantidade de documentos com a conjunção água produzida 
e filtração foram elevados, principalmente na base SCIENCE DIRECT® chegando a quase 120000 publicações. Quando relacionado com o maracujá e água produzida chegou-se a encontrar uma quantidade significante de 1204 artigos científicos e para filtração e maracujá 270 exemplares. Entretanto, os resultados para a junção das três palavraschaves foi pequeno em comparação com os demais, onde nas bases WEB OF SCIENCE® e SCOPUS® não houveram artigos publicados, encontrando-se apenas 170 trabalhos na SCIENCE DIRECT®, evidenciando a necessidade de mais pesquisas nessa área.

Figura 1 - Número de artigos publicados nas bases de buscas de acordo com as palavraschaves.

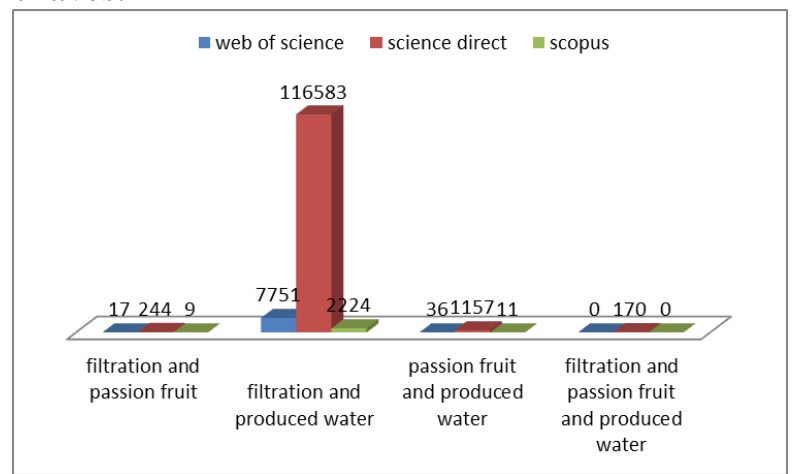

Fonte: Elaboração própria (2015).

A partir de uma avaliação mais a fundo na base SCOPUS $®$ notou-se que $73 \%$ dos documentos cujo tema refere-se à água produzida e maracujá foram produzidos no Brasil, sendo este valor 8 de um total de 11 trabalhos, provavelmente isso deve-se ao fato desse fruto ser nativo das zonas tropicais e subtropicais da América. Como mostra a Figura 2.
Figura 2 - Distribuição dos artigos relacionados à água produzida e maracujá por país de origem entre 2001-2015 de acordo com SCOPUS®.

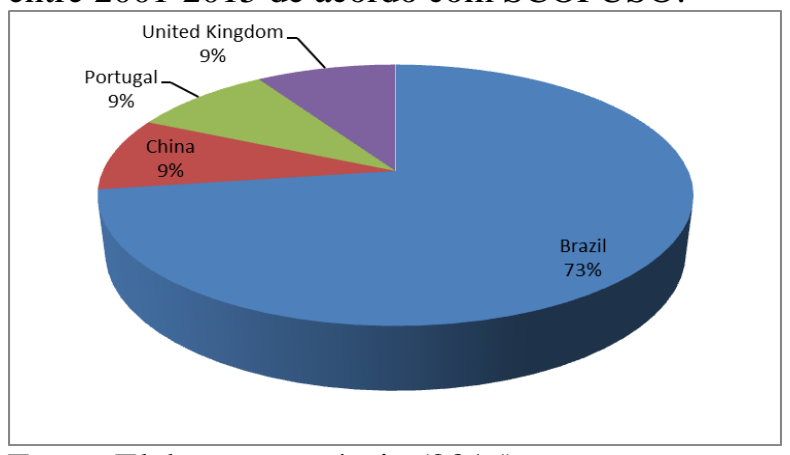

Fonte: Elaboração própria (2015).

Como mostra a Figura 3, que expõe as áreas vinculadas desses artigos encontrados na mesma base de pesquisa e com mesmo tema, a maioria está associado com agricultura e biologia sendo uma minoria de ciência ambiental, reforçando a importância de mais estudos envolvendo tal assunto.

Figura 3 - Àreas vinculadas aos artigos relacionados à água produzida e maracujá entre 2001-2015 de acordo com SCOPUS®.

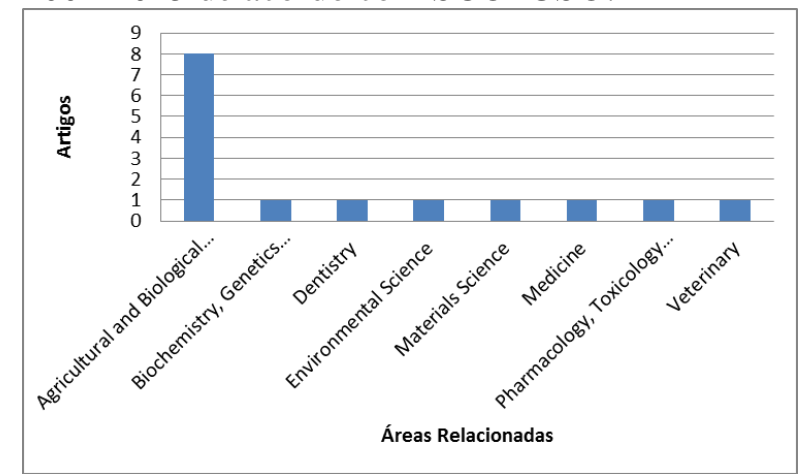

Fonte: Elaboração própria (2015).

Fazendo essas mesmas análises, mas agora com a associação de filtração e maracujá nota-se novamente a predominancia de documentos publicados no Brasil, correspondendo a 60\%, como mostra a Figura 4. 
Figura 4 - Distribuição dos artigos relacionados à filtração e maracujá por país de origem entre 2001-2015 de acordo com SCOPUS®.

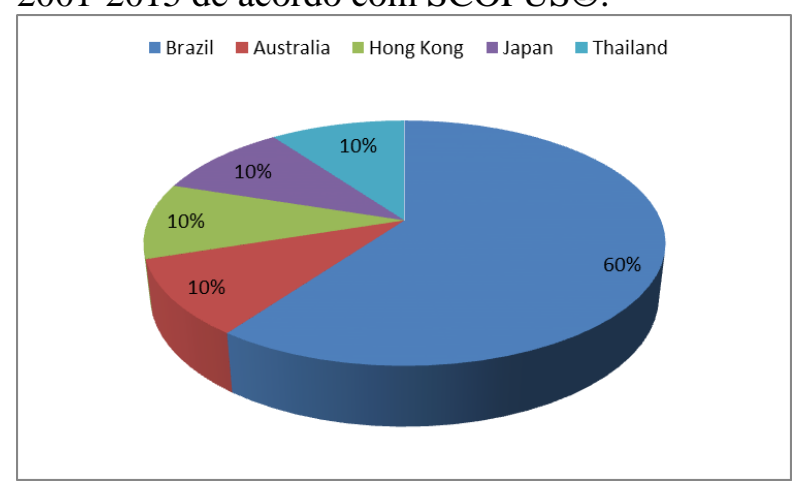

Fonte: Elaboração própria (2015).

Como mostra a Figura 5, que vem reforçar a escassez de publicações em setores que envolvem o tratamento de efluentes tendo em vista que não há atribuição a ciência ambiental nem a outra área correlacionada ao tratamento de efluentes, prevalencendo, novamente, as ciências agrárias e biológicas.

Figura 5 - Àreas vinculadas aos artigos relacionados à água filtração e maracujá entre 2001-2015 de acordo com SCOPUS®.

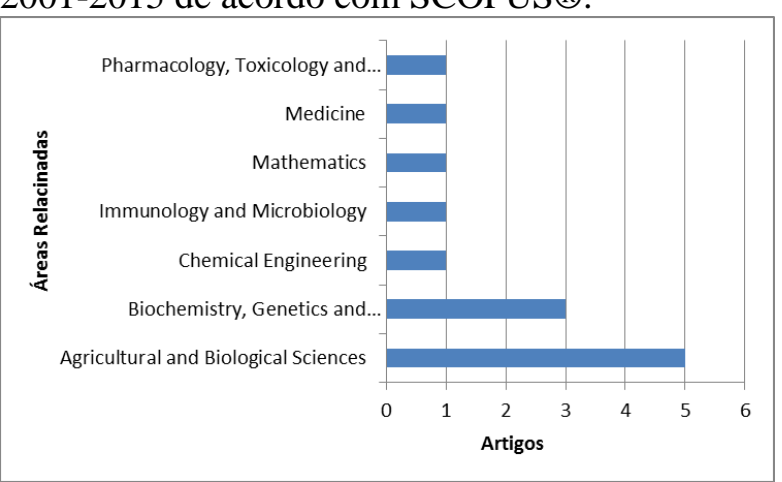

Fonte: Elaboração própria (2015).

Outro ponto interessante, fornecido pela WEB OF SCIENCE® e como mostram as Figuras 6 e 7, é que grande parte dos artigos envolvendo tanto filtração e maracujá quanto água produzida e maracujá foram divulgados nos últimos cinco anos, representados pelas porcentagens de $47 \%$ e $55,5 \%$, respectivamente. Isso evidencia o quão recentes são as pesquisas vinculadas a esse tipo de conteúdo.

Figura 6 - Quantitativo de artigos relacionados à filtração e maracujá desde o ano de 2001 de acordo com WEB OF SCIENCE®.

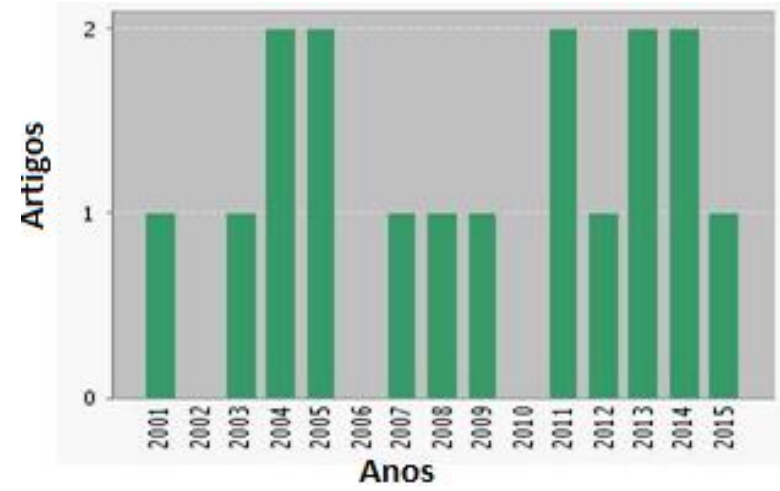

Fonte: Elaboração própria (2015).

Figura 7 - Quantitativo de artigos relacionados à água produzida e maracujá desde o ano de 2001 de acordo com WEB OF SCIENCE®.

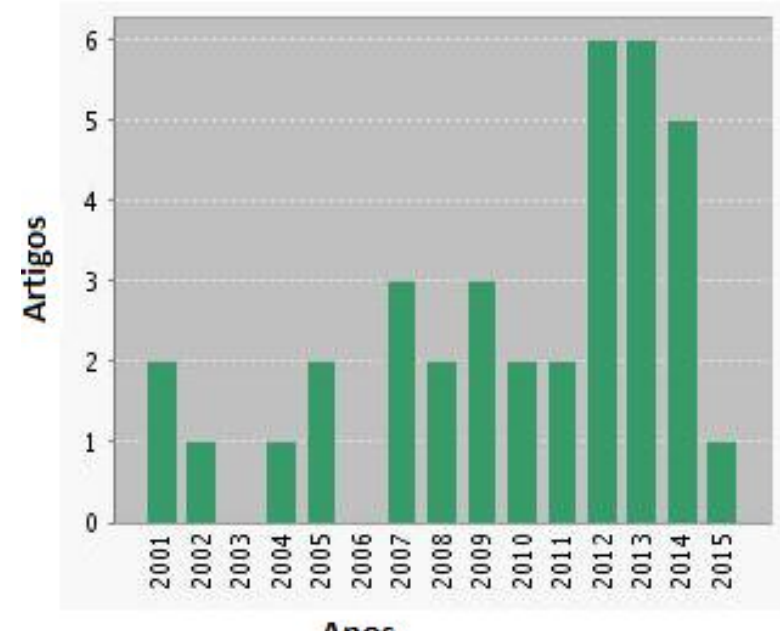

Fonte: Elaboração própria (2015).

\section{CONCLUSÃO}

Os dados apresentados com a prospecção mostram que há necessidade de mais estudos do uso do maracujá como meio filtrante, principalmente no tratamento de água produzida. Tendo em vista que os trabalhos encontrados envolvendo tal área foram mínimos. Quando combinou-se as três palavras-chave encontrou-se trabalhos apenas 
na SCIENCE DIRECT ${ }^{\circledR}$ acentuando a carência de artigos científicos que englobem o maracujá aplicado na filtração de água produzida. Além disso, de acordo com a SCOPUS $®$, apesar do Brasil representar a maioria dos documentos publicados com a combinação água produzida e maracujá e também, filtração e maracujá o foco dos estudos estão direcionado as Ciências agrárias e biológicas e não ao tratamento de efluentes. Para alterar essa situação propõe-se mais pesquisas envolvendo tal tema de modo a proporcionar o desenvolvimento de novas tecnologias no tratamento de água produzida, já que esta é um efluente que precisa ter um fim adequado para minimizar os impactos ambientais negativos.

\section{REFERÊNCIAS}

COELHO, G. M. Prospecção tecnológica: metodologias e experiências nacionais e internacionais: tendências tecnológicas: nota técnica 14. Rio de Janeiro: Instituto Nacional de Tecnologia, 2003. Projeto CTPETRO.

MONDAL, S.; WICKRAMASINGHE, S. R. Produced water treatment by nanofiltration and reverse osmosis membranes.Journal of Membrane Science. v. 332. P. 162-170, 2008.

STEPHENSON, M. T. Components of produced water: a compilation of results from several industry studies. SPE n.23313, p. 25-38, 1991. 